\title{
BIOATIVOS DA CAATINGA PARA USO COSMÉTICO
}

\author{
Elizabete Regina Silva Lucena dos Santos ${ }^{1}$, Sergio de Oliveira Gomes ${ }^{1 *}$, Rafael Jorge Santos Aracati Padilha ${ }^{1}$, \\ Leylianne de Cassia Rodrigues Nerys ${ }^{1}$, Ricardo Yara ${ }^{2}$, Cláudia Sampaio de Andrade Lima ${ }^{1}$ \\ ${ }^{1}$ Laboratório de Biofísica Química, UFPE; ${ }^{2}$ Laboratório de Engenharia Biomédica, UFPE \\ *sgomes1904@hotmail.com
}

\section{INTRODUÇÃO}

O corpo humano produz naturalmente radicais livres através do metabolismo oxidativo, que conduzem ao envelhecimento afetando diversos órgãos incluindo a pele, promovendo a oxidação de membranas celulares, proteínas e consequente diminuição de colágeno e elastina. Compostos que diminuem essa ação são chamados de antioxidantes e podem ser encontrados como parte do metabolismo de algumas espécies de plantas (FREITAS, 2000).

o metabolismo oxidativo é o principal condutor no processo progressivo e natural do envelhecimento, no qual ocorrem modificações morfológicas, psicológicas, funcionais e bioquímicas que reduzem a capacidade de adaptação do indivíduo ao meio ambiente, afetando sua integridade e tendo grande impacto sobre a saúde e a qualidade de vida do idoso com o surgimento de danos a pele e mucosas e também aparecimento de doenças crônicas associadas ao envelhecimento, como doenças cardiovasculares, hipertensão, diabetes, artrite reumatóide e doenças neurodegenerativas (doença de Alzheimer, doença de Parkinson) (HAYFLICK, 2007; FERRARI et al., 2009; JELLINGER, 2007).

Uma solução para reduzir o processo oxidativo está em recorrer para investigação do conhecimento empírico relacionado a ação de antioxidantes encontrados em plantas do nordeste brasileiro, especificamente no ecossistema da Caatinga, que é ú nico no mundo e cobre quase 1 milhão de $\mathrm{km}^{2}$ no Nordeste do Brasil. A vegetação xerófila é uma grande característica, consequê ncia dos grandes e irregulares períodos de seca, altas temperaturas e elevada radiação ultravioleta, devido a essas características ú nicas houve o desenvolvimento em abundância de espécies com potenciais compostos para serem utilizados em cosméticos antioxidantes, cura de doenças e diversos outros fins fármacos. (FREITAS, 2000; FERRARI; SILVA, 2011).

A partir desse contexto o presente trabalho buscou por objetivo investigar o potencial antioxidante de dez plantas coletadas na caatinga, em região do semiárido Pernambucano.

\section{MATERIAIS E MÉTODOS}

As espécies foram coletadas em regiões do semi-árido Pernambucano. As espécies foram coletadas na cidade de Brejo da Madre de Deus, Caruaru, Garanhuns e nas regiões do semi-árido Pernambucano. 0 trabalho analisou folhas e partes aéreas das espé cies: Melissa officinalis (Erva cidreira), Acacia glomerosa (Espinheiro), Cordia goeldiana (Freijó), Plectranthus amboinicus (Hortelã miúda), Dysphania ambrosioides (Mastruz), Bauhinia forficata (Mororó), Bryophyllum pinnatum (Corama Branca), Artemisia vulgaris (Artemísia), Myracrodruon urundeuva (Aroeira do Sertão) e Alternanthera brasiliana (Terramicina). 0 método utilizado para analise antioxidante foi por DPPH. Adicionaram-se $1,0 \mathrm{~mL}$ da solução das amostras a serem testadas em $1,0 \mathrm{~mL}$ de solução do radical DPPH. As misturas foram mantidas em repouso, sob proteção de luz, por 30 minutos. Logo após, foram lidas as absorbâncias a $517 \mathrm{~nm}$ em espectrofotômetro UV/Vis e realizado o calculo da capacidade sequestrante.

\section{RESULTADOS E DISCUSSÃO}

Como resultado, obtivemos uma alta porcentagem da atividade sequestrante de extrato etanólico $(1 \mathrm{mg} / \mathrm{mL})$ no ensaio de DPPH por extrato avaliado (Tabela 1).

Tabela 1. Porcentagem da atividade sequestrante por extrato.

\begin{tabular}{ccc}
\hline Espécie & Nome popular & $\begin{array}{c}\text { Potencial } \\
\text { antioxidante }\end{array}$ \\
\hline Melissa officinalis & Erva cidreira & $85 \%$ \\
Acacia glomerosa & Espinheiro & $86 \%$ \\
Cordia goeldiana & Freijó & $93 \%$ \\
Plectranthus & Hortelã miúda & $83 \%$ \\
amboinicus & & \\
Dysphania & Mastruz & $78 \%$ \\
ambrosioides & Mororó & $85 \%$ \\
Bauhinia forficata & Corama Branca & $76 \%$ \\
Bryophyllum pinnatum & Artemísia & $74 \%$ \\
Artemisia vulgaris & Aroeira do Sertão & $92 \%$ \\
Myracrodruon & & $84 \%$ \\
urundeuva & Terramicina & \\
Alternanthera & & \\
brasiliana & &
\end{tabular}

A homeostase corporal é interrompida quando há um desiquilíbrio entre a relação de formação de radicais livres e a açã o dos antioxidantes no organismo, ocorrendo o estresse oxidativo, podendo acarretar no envelhecimento precoce. Muitas espécies do semiárido Pernambucano vêm se mostrando como potencial fonte de antioxidantes para utilização em fármacos e cosméticos.

$\mathrm{Na}$ literatura cientifica já é demonstrado o potencial o potencial anti-inflamatório e cicatrizante de algumas plantas. Nos resultados desse estudo, foram comprovadas as altas taxas de atividade antioxidante que tais espécies possuem, a partir dessas informações podemos inferir que os mesmos podem estar relacionados a compostos fenólicos presentes nas plantas analisadas.

\section{CONCLUSÕES}

Diante dos resultados obtidos no presente trabalho, fica claro o grande potencial dessas espécies para serem utilizadas em uma gama de produtos cosméticos antioxidantes a base de plantas medicinais da região do semi-árido, contudo, ainda se faz necessá 
rio estudos mais específicos com o isolamento e a caracterização desses compostos.

Apoio:

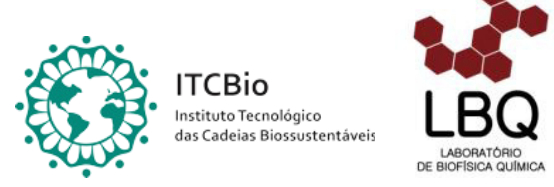

\section{REFERÊNCIAS}

HAYFLICK L. Biological aging is no longer an unsolved problem. Ann. NY Acad Sci 2007;1100(1):1-13.

FERRARI, C.K.B.; FRANÇA, E.L.; HONORIO-FRANÇA, A.C. Nitric oxide, health and disease. J Appl Biomed;7:163-73. 2009.

JELLINGER, K.A. Advances in our understanding of neurodegeneration. In: Qureshi GA, Parvez SH. Oxidative stress and neurodegenerative disorders. Amsterdam: Elsevier. p.1-58, 2007 FREITAS, P. C. D. Atividade antioxidante de espécies medicinais da família Piperaceae: Pothomorphe umbellata (L.) Miq. e Piper regnellii (Miq.) C. DC. 2000. Tese (Doutorado em Insumos Farmacê uticos) - Faculdade de Ciências Farmacêuticas, University of São Paulo, São Paulo, 2000. doi:10.11606/T.9.2000.tde-28082008104803. Acesso em: 2017-12-06

SILVA, W. J. M.; FERRARI, C. K. B. Metabolismo Mitocondrial, Radicais Livres e Envelhecimento Mitochondrial Metabolism, Free Radicals and Aging. Rev. bras. geriatr. gerontol. [online]. vol.14, n.3, pp.441-451. ISSN 1981-2256. 2011 